\title{
Dust-Emission from Abrasive Sanding Processes in the Malaysian Wooden Furniture Industry
}

\begin{abstract}
A series of sanding experiments were carried out in a large dust tunnel, using an orbital sander with an aluminum oxide abrasive of 150 grit size, on twelve different hardwood species. Dust concentration measurements were taken using gravimetric isokinetic air-quality samplers. A field survey of 25 wooden furniture-manufacturing mills to ascertain the dust exposure levels at the sanding sections and also evaluate the labor productivity losses encountered among workers as a result of dust exposure. The results found that dust emission in the sanding process was primarily determined by the amount of wood removed. Further, the dust exposure levels at the sanding section in the furniture-manufacturing mills were above the standard $5 \mathrm{mg} \mathrm{m}-3$ level and hence, control of dust emission and the use of dust protection gears by the workers must be enforced in the furniture-manufacturing mills to ensure the health and safety of the workers. Without such measures, labor productivity among the workers would be reduced.
\end{abstract}

Keyword: Wood dust, furniture, wood removal, health, productivity 